\title{
Una aproximación a las iniciativas de conservación cultural y reutilización del legado minero industrial del Bierzo y Laciana (León, España) ${ }^{1}$
}

Jorge Magaz Molina ${ }^{a}$

${ }^{a}$ Escuela de Arquitectura de la Universidad de Alcalá. Santa Úrsula 8, 28801, Alcalá de Henares (Madrid-España). jorge.magaz@edu.uah.es.

\begin{abstract}
Resumen
Se exponen los primeros resultados de la investigación doctoral en curso sobre los procesos de transformación y potencialidades de recuperación para el desarrollo local del paisaje minero e industrial de las comarcas leonesas del Bierzo y Laciana (España). Se presenta una revisión general de las iniciativas de inventariado desarrolladas, el alcance de las mismas, y su trasposición a figuras de conservación del planeamiento urbano; el grado de protección vigente de un patrimonio emergente: el legado minero industrial; las iniciativas públicas y privadas de reutilización o musealización llevadas a término o interrumpidas; la conservación del legado documental de las empresas mineras; las estrategias planteadas para la coordinación y difusión del patrimonio minero industrial.
\end{abstract}

Palabras clave: archivo de empresa, Carta del Bierzo, inventario de patrimonio, museo minero, paisaje minero, patrimonio documental, patrimonio industrial, patrimonio minero, turismo industrial.

\begin{abstract}
The first results of the current doctoral research on the transformation processes and recovery potentials for the local development of the mining and industrial landscape of the León regions of Bierzo and Laciana (Spain) are presented. A general review of the industrial heritage inventory initiatives developed, their scope, and their transposition to urban planning conservation figures is presented. This work also describes the current degree of protection of the industrial mining legacy; public and private reuse or musealization initiatives carried out or discontinued; preserving the documentary legacy of mining companies and the strategies proposed for the coordination and dissemination of the industrial mining heritage.
\end{abstract}

Keywords: business archives, Bierzo Charter, heritage inventory, mining museum, mining landscape, documentary heritage, industrial heritage, mining heritage, industrial tourism.

\footnotetext{
${ }^{1}$ Este trabajo está enmarcado en el proyecto de investigación en curso: La imagen del Instituto Nacional de Industria en el territorio: cartografia y paisaje de la industria del Ministerio de Ciencia, Innovación y Universidades. Programa Estatal de Generación de Conocimiento y Fortalecimiento Científico I+D+i. Convocatoria 2018. Ref. PGC2018-095261-B-C22. Investigadora Principal: Ángeles Layuno Rosas.
} 


\section{Introducción}

El paisaje de las comarcas del Bierzo y Laciana (León, España) ilustran, como pocos en Europa, la evolución en el tiempo y en el territorio de las actividades minero-extractivas, que se extienden desde sus inicios, con la minería aurífera romana, hasta nuestros días, pasando por las explotaciones medievales y modernas de hierro, o la extracción de wólfram y carbón del siglo XX. La tardía explotación a escala industrial de los recursos minerales durante el siglo pasado supuso una acelerada transformación socioeconómica de estos territorios, que se situaron en el siglo XX como uno de los polos de crecimiento más importantes del país. Sin embargo, a partir de la década de 1960 se evidenció ya la debilidad del tejido minero, sobredimensionado por la Autarquía, así como la fuerte dependencia de las comunidades locales respecto de este sector. Si bien las actividades mineras continúan hoy en forma de canteras de caliza y pizarra, el cierre de las últimas explotaciones de carbón del valle del Sil, el 31 de diciembre de 2018, se interpreta, junto al anuncio, en septiembre 2019, del cierre de las últimas centrales térmicas de la zona, como el final de un ciclo económico basado en el consumo de recursos fósiles. Esta situación exige un ineludible proceso de reconversión que se arrastra desde las últimas tres décadas, hoy rebautizada como "transición justa".

Un vasto legado edificado, tecnológico y documental queda como testimonio de las actividades industriales en extinción, desarrolladas en estos territorios en el último siglo por las empresas mineras, de transformación y/o distribución de mineral y centrales de producción eléctrica. Superadas las nociones monumentalistas, la aproximación actual al patrimonio se orienta hacia una valoración integral de los elementos materiales e inmateriales que configuran un territorio y su percepción, y sitúa la noción de paisaje como figura multidimensional (Cañizares, 2011) susceptible de ofrecer un guion interpretativo centrado en la cultura del trabajo (Andrieux, 1992), en el que inscribir la sensibilidad hacia el legado industrial y minero. Y si bien las aproximaciones patrimoniales tuvieron una tardía acogida por parte de los gestores locales, desde finales de la década de 1990 la puesta en valor de los enclaves más icónicos ligados al pasado minero-industrial se ha planteado como potencial recurso que tiende a incluirse en la incipiente oferta turística, planteándola como una de las líneas de diversificación económica con la que garantizar la supervivencia de las comunidades locales. Se echa en falta, sin embargo, una política cultural planificada a escala territorial y coordinada entre las distintas administraciones y agentes interesados, que contemple un estudio previo con el que abordar de forma global el desarrollo del fenómeno industrial, sus procesos, etapas y relaciones; se necesita analizar el estado actual en que se encuentran las instalaciones y sus potenciales usos, como paso previo a la definición de una estrategia de reactivación territorial y patrimonialización del paisaje minero.

"La Carta de El Bierzo para la Conservación del Patrimonio Industrial Minero", promovida en 2007 por el Instituto del Patrimonio Cultural de España, como base conceptual y metodológica de ámbito estatal para las actuaciones de recuperación del legado minero (Cañizares, 2011), ofreció un horizonte alentador complementario a la estrategia autonómica definida en el Plan PAHIS del Patrimonio Histórico de Castilla y León (2004-2012, 2015-2020), que atendía a la diversidad de tipologías del «patrimonio industrial», y sugería la puesta en práctica de actuaciones de conservación cultural articuladas territorialmente en base a la noción de "sistemas territoriales de patrimonio", entendidos como unidades de paisaje. Estas cuestiones, junto al análisis de las transformaciones urbanas que sucedieron a las primeras etapas de la reconversión minera (Alonso Santos, 2011), o al estudio de los planes de incentivación turística que se plantearon en las primeras décadas del siglo XXI (Benito et al., 2008; Hidalgo, 2011; Monteserín, 2008), quedaron recogidas en distintos trabajos que advertían de la lentitud de los procesos administrativos; por entonces se aplazaban ya la puesta en práctica de proyectos de conservación cultural y reutilización turística (Hortelano, 2011b), de impulso autonómico y/o estatal, como los recogidos en el Listado de Actuaciones del Nuevo Plan del Carbón 2006-2012, que arrastraba propuestas de 1998, y que quedarían reducidos o interrumpidos a consecuencia de la crisis.

Con una década de distancia respecto a esos trabajos, la comunicación presentada en el I Congreso de ICOMOS planteaba ofrecer un nuevo acercamiento general a la situación actual del legado edificado y documental de la minería y la industria de estos territorios. 


\section{Horizonte del legado minero industrial del Bierzo y Laciana}

Si bien las industrias vivas constituyen en sí mismas un recurso interpretativo, el cierre y abandono de instalaciones industriales y mineras representa un importante desafío cultural, urbanístico, ambiental y territorial desde la década de 1970, en el que se conjugan resistencias al cambio, intereses económicos e inmobiliarios, oportunidades de innovación y reposicionamiento y aproximaciones patrimoniales. El cierre escalonado de explotaciones mineras e industrias asociadas del Bierzo y Laciana (en las décadas 1960-70, 1980-90, y 2010-19) ofrece un buen ejemplo de las problemáticas de la "ruina industrial" y el "abandono" de instalaciones (Conti, 2011), situación que ha seguido patrones comunes a un fenómeno global (Cueto, 2009), teniendo especial impacto sobre los espacios productivos; pues, cuando no son objeto de presión inmobiliaria, acaban sufriendo un grave proceso de deterioro. Son susceptibles de salvarse de este deterioro los espacios de la esfera social de la industria (barriadas, poblados, sanatorios, economatos, etc.) mientras se mantenga una actividad terciaria y residencial, condicionada, en estos territorios, a su proximidad a núcleos de población.

Desarrollada en el marco del Plan Nacional de Patrimonio Industrial del Instituto del Patrimonio Cultural de España (IPCE), adscrito al Ministerio de Cultura; y publicada en 2008, La Carta de El Bierzo apremiaba a aunar esfuerzos entre los distintos niveles administrativos, empresas y movimientos ciudadanos para preservar los valores propios de los bienes vinculados a la explotación minero-industrial; concretaba para ello un marco metodológico basado en el inventariado, selección de elementos singulares para la aplicación de grados de protección adecuados, y niveles de protección jurídica; intervenciones de revalorización, planes de conservación preventiva, y el desarrollo de políticas de difusión pública. Siguiendo este guion, a continuación, se exponen los resultados del estudio desarrollado sobre las iniciativas de conservación acometidas en el Bierzo y Laciana, entendiendo estos territorios como un espacio productivo único.

\subsection{Iniciativas de inventariado y catalogación}

Las primeras investigaciones sobre la dimensión patrimonial de la industria local de estos territorios se remontan a finales de los noventa, como la de Balboa de Paz (1997), o el Inventario Monumental que publicó en 1998 la Concejalía de Cultura de Ponferrada. Las instalaciones mineras también se incluyeron poco después en los Inventarios de Recursos Endógenos que elaboraron algunos ayuntamientos, como Villablino o Fabero, entre 2005-2009.

Desde la administración autonómica se promovió el Inventario del Patrimonio Industrial de Castilla y León, entre 2008 a 2010, coordinado por la Dirección General de Patrimonio Cultural de la Consejería de Cultura y Turismo. Elaborado por provincias, y redactando fichas de "bienes", o puntualmente de "conjuntos", ofrece un censo bastante completo que incluye las instalaciones mineras más representativas, instalaciones fabriles anteriores a 1960, molinos maquileros y ferrerías. Incorpora unos 310 bienes en los municipios del Bierzo y Laciana, que se desglosan en 147 molinos, 18 ferrerías/fraguas y serrerías, 73 instalaciones mineras, 26 instalaciones ferroviarias, 49 fábricas y fábricas de luz. El registro de instalaciones de la segunda mitad del siglo XX de producción y transporte eléctrico, cementeras o fábricas de materiales de construcción es escaso. Lagares y bodegas, cooperativas agrícolas apenas se recogen, y se estima débil la representación de la esfera social de la industria: de los 40 asentamientos que se pueden identificar en el valle del Sil, el inventario registra sólo 4 "poblados", y apenas atiende a las instalaciones complementarias de las compañías mineras (almacenes, escuelas, economatos...), o presta escasa atención a la arquitectura residencial y a los equipamientos privados del paisaje urbano industrial. Los resultados de la provincia de León no han sido publicados, si bien, bajo solitud, se pueden consultar online las fichas recogidas. Se echa en falta la divulgación de los criterios seguidos por los distintos equipos responsables, así como la definición espacial de las instalaciones inventariadas, en SIG, como se planteaba en origen (Benito del Pozo, 2009, p. 186), con la que identificar el alcance de los bienes registrados, y una visión de conjunto sobre la que reconocer relaciones funcionales. En relación, a las políticas de conservación, no se puede pasar por alto que este trabajo no ha tenido trasposición al planteamiento local o territorial.

En fechas similares, la Fundación CIUDEN, adscrita a la Administración Central, encargó la redacción de un inventario de patrimonio minero-industrial del Bierzo y Laciana, elaborado entre 2007-2009. De alcance similar, atiende a 
potenciales usos alternativos, y recoge testimonios de memoria oral, así como otros recursos culturales y naturales de la zona. También sin publicar, no consta que ofrezca definición gráfica espacial, y su consulta ha de realizarse en sala.

En el marco del proceso de desafección de la vía del tren minero Ponferrada-Villablino, construido en 1918 como vertebrador de la minería del valle del Sil, la Dirección General de Carreteras e Infraestructuras de Castilla y León encargó en 2017 un pormenorizado inventario de los bienes que integraron esta instalación, destinado a su registro catastral como bien demanial. Tras la entrada en Proceso Concursal de Coto Minero del Cantábrico (CMC) en 2014, la concesión ferroviaria entró en fase de liquidación, por lo que hubo que esperar hasta la resolución del contrato para iniciar la regulación catastral que ha incluido la alteración de 265 fincas colindantes o afectadas. La renovación de la concesión de la línea, reducida al trayecto de Cubillos a Villablino en 1998, no se acompañó del inventariado y registro de bienes; únicamente se prolongó la concesión limitada al transporte de carbón, lo que ha obligado a la realización del inventario en dos fases, el tramo Cubillos-Villablino, y el tramo Ponferrada-Cubillos, prácticamente desmantelado.

En 2018 UGT presentó un "mapa del patrimonio industrial minero" de Castilla y León como base de su "catálogo de bienes de turismo en áreas mineras", si bien estos contenidos no se distinguen demasiado de aquellos recogidos en el inventario impulsado por la Dirección General de Patrimonio diez años antes, y tampoco profundiza en un análisis sobre el estado de conservación, propiedad actual, seguridad estructural, o adaptabilidad para aprovechamientos turísticos.

\subsection{Grado de protección vigente del legado minero industrial}

El entorno del itinerario del Camino Francés a Compostela y el paraje de Las Médulas han sido inscritos en la Lista de Patrimonio Mundial de la Humanidad, en 1993 y 1997 respectivamente, y a su alrededor se ha ido tejiendo un incipiente sector turístico que, sin llegar a suplir, ni mucho menos, el impacto económico generado tras la desindustrialización ha conseguido mantener vivos o incluso recuperar una buena parte de un rural lastrado por la despoblación. Ayuntamientos mineros como Torre del Bierzo y Brañuelas apuestan por plantear ramales de peregrinación alternativos por sus municipios, como también se plantea por el valle del Sil. Figuras de protección natural se han asignado a la Sierra Ancares-Alto Sil, Laciana y a los Montes Aquilianos, declaradas Espacio Natural (2002-2006), Reserva de la Biosfera (2003) y ZEPAS+LIC respectivamente.

De los 237 bienes declarados BIC en la provincia de León, sólo 8 se pueden interpretar ligados al pasado reciente industrial y minero de la provincia: la herrería de Compludo (1968), la plaza cerrada y los restos del Alto Horno de Sabero (1991), la fábrica de Productos Químicos de León (1991), el Hotel Alfonso V de León (1991), la casa del empresario minero González Vega en León (1997), la Casa Botines (2002), el conjunto del Pozo Ibarra de la Pola Gordón (2011), y en 2019 se incoó el expediente de declaración del "Conjunto etnográfico de Fabero". La conservación del legado edificado del pasado minero e industrial de estos territorios queda así, únicamente, al amparo de las figuras locales de protección que las distintas regulaciones urbanísticas definan con mayor o menor sensibilidad, o en el mejor de los casos, su inclusión en los Catálogos de los PGOU.

La falta de desarrollo de la figura administrativa representada en los sistemas territoriales de patrimonio, incluida en el Plan PAHIS como instrumento de gestión del paisaje minero del Bierzo y Laciana, podría explicar la heterogeneidad de criterios de selección, así como la ausencia de aproximaciones de conjunto, evidenciando la escasa aplicación de los criterios establecidos en la Carta del Bierzo, que recomienda la protección jurídica de los elementos que componen el complejo de explotación y la conservación de los elementos más significativos. En el mejor de los casos, se han identificado catalogaciones y ordenanzas de protección fragmentarias, a menudo guiadas por la representatividad de piezas icónicas, que obvian la interrelación de los 3 sistemas que comprende el espacio productivo industrial (Goodall y Beech, 2006): los edificios e instalaciones de trabajo, las instalaciones de transporte y producción de fuentes de energía, y las vías de comunicación. En este sentido, se puede hablar de "chimeneismo" o "castilleteismo" en el Catálogo de Villablino. Por otro lado, la habitual escasa consideración de la esfera social de la industria en las ordenaciones urbanas contrasta con el reconocimiento del BIC de Fabero al "poblado de Diego Pérez". Grado de protección patrimonial autonómica que, sin embargo, deja fuera al barrio de San Nicolás de Fabero, promoción de vivienda obrera 
característica de las localidades mineras de la zona impulsada por la Obra Sindical del Hogar en 1955. Presente también en Toreno, Matarrosa, o Ponferrada, estas poblaciones tampoco le asignan figura de protección alguna.

\subsection{Reutilización del legado edificado de la minería y la industria del Bierzo y Laciana}

Como se ha señalado, la localización de las distintas instalaciones ha planteado un destino desigual. La presión urbanística sobre las propiedades de MSP explican el derribo de piezas de gran valor, como el economato o las instalaciones ferroviarias y fabriles de MSP en Ponferrada entre 1996 y 2004. Promesas de regeneración económica explican, por otro lado, el derribo de la cementera de Parandones para puerto seco del Musel (2003), la sustitución de los antiguos cuarteles mineros de Almagarinos por los invernaderos de la Fundación CIUDEN, o el derribo promovido por Turespaña en 2011 de las antiguas Escuelas de Villablino, con destino a Parador Nacional de Turismo, proyectos todos nunca completados.

Por otro lado, no se puede pasar por alto el mantenimiento del uso industrial de las instalaciones más próximas a los ejes de transporte por carretera, como el Coto Vivaldi, o la adaptación de los cargaderos de carbón de la Placa en Ponferrada, o los talleres de madera de MSP de Las Rozas-Villablino. Esa misma meta se propone para los solares de las últimas térmicas, Compostilla II y Anllares; no obstante, no parece haberse planteado una valoración previa de su valor cultural, como tampoco el de las instalaciones hidroeléctricas promovidas por el Instituto Nacional de Industria el siglo pasado.

Si bien se puede concluir que la conservación del legado minero o industrial no estuvo dentro de la agenda de la reconversión minera e industrial, se pueden identificar políticas sensibles al patrimonio transversalmente en iniciativas de mejora de la vivienda, como las rehabilitaciones acometida en los cuarteles de Villablino (2005), o en la barriada de MSP de Flores de Sil en Ponferrada (2006). Las ayudas a la mejora de la urbanización de las localidades también han materializado iniciativas de promoción de la memoria minera, con el despliegue de maquinaria y estructuras mineras en el espacio público. En este sentido se puede mencionar el “jardín minero” de Almagarinos o Montealegre; la recreación en Brañuelas de la "Mina Rinconín”, bajo el pontón ferroviario, o la instalación de las torretas de las antiguas líneas de baldes en zonas de esparcimiento en Torre del Bierzo y Brañuelas, entre otras actuaciones.

\subsubsection{Museos y equipamientos interpretativos del pasado minero e industrial}

La contribución de la reutilización turística del legado minero se ha comprobado como una estrategia con un amplio desarrollo global en las últimas décadas (Conlin et al., 2010), teniendo en cuenta que las cuestiones de escala y localización juegan un papel de desventaja frente a otras alternativas como equipamientos, usos residenciales o el sector terciario, que ofrecen los espacios industriales y mineros urbanos. En este sentido, desde finales de la década de 1980 , distintos territorios del Estado Español han buscado en el "turismo minero" e "industrial" una diversificación económica al monocultivo de la actividad minera e industrial, poniendo en valor su pasado minero.

Pese al significativo papel del Bierzo y Laciana en la producción energética, estos territorios se caracterizaron hasta finales del siglo XX por constituir territorios marcados por cierto subdesarrollo. Las ayudas de los fondos mineros (1991-2012) estuvieron centradas en equilibrar las desigualdades territoriales, impulsando la mejora de comunicaciones, la creación de suelo y de tejido industrial, la ordenación del territorio, la protección del medio ambiente, abastecimiento y saneamiento de aguas; fomento de la educación; mejora de las condiciones de vivienda y del urbanismo, y la creación o mejora de infraestructuras agrícolas, ganaderas y turísticas.

Más allá de la iniciativa de la familia propietaria de la herrería decimonónica de Compludo por hacerla visitable desde la década de 1980, hasta finales de la década de 1990 no constan proyectos de puesta en valor del patrimonio minero e industrial de la zona (Tabla 1). El primero de ellos, el museo municipal del ferrocarril de Ponferrada fue inaugurado en 1997, y se instala en el solar de la antigua estación del tren minero de MSP, de la que sólo se conserva el edificio de viajeros. A 1998 se remonta la propuesta de un "parque minero en Fabero", planteada dentro de los acuerdos entre administración central y autonómica para desarrollar proyectos de ocio y turismo en las comarcas mineras de la comunidad, junto a otros proyectos como los de Barruelo de Santullán, Sabero, o San Cebrián de Mudá. Sin embargo, como apunta Hortelano (2011a, p. 27; 2011b, p. 301), la lentitud en ejecutar estas iniciativas obligará a incluir de nuevo 
este proyecto en el anexo de Actuaciones del Convenio Marco de Colaboración del Nuevo Plan del Carbón 2006-2012, al que se suma el Ecomuseo de Bembibre, entre otras propuestas.

En paralelo a las iniciativas del Plan del Carbón, varios ministerios constituyen en 2006 la Fundación CIUDEN con varios objetivos: la promoción de un polo de investigación científica sobre energía y técnicas de rehabilitación ambiental en la zona, y el desarrollo socio económico de estas comarcas a través del turismo cultural (Hidalgo, 2011). En el marco de la política de descentralización de los museos nacionales, se promueve la rehabilitación de las centrales térmicas de MSP y ENDESA de Ponferrada para alojar el "Museo Nacional de la Energía" (Aparicio, 2019), concebido como puerta de un "territorio museo" para el que se había desarrollado en 2011 una planificación estratégica.

En la década del 2000 se identifica un cambio de sensibilidad de las administraciones locales hacia la puesta en valor de espacios productivos emblemáticos en las distintas localidades. En 2005 los ayuntamientos de Ponferrada, Cubillos del Sil, Toreno, Páramo del Sil, Palacios del Sil y Villablino constituían un consorcio para impulsar un tren turístico sobre la vía del tren minero Ponferrada-Villablino; y ese mismo año se constituía la Fundación Memoria Minera para impulsar iniciativas culturales e interpretativas de la minería en la zona del Alto Bierzo. En 2007 Villablino planteaba la musealización del Pozo María, y en Páramo del Sil se apostaba por construir una recreación minera, entre otras iniciativas.

Tabla 1. Iniciativas de musealización del legado de la minería y la industria del Bierzo y Laciana

\begin{tabular}{|c|c|c|c|c|c|c|c|}
\hline Municipio & Instalación en origen & Destino propuesto & $\begin{array}{c}\text { Fecha } \\
\text { propuesta }\end{array}$ & Promotor & $\begin{array}{l}\text { Inicio } \\
\text { obras }\end{array}$ & $\begin{array}{l}\text { Grado de } \\
\text { ejecución }\end{array}$ & Apertura \\
\hline \multirow[t]{2}{*}{ BEMBIBRE } & (obra nueva) & $\begin{array}{c}\text { Ecomuseo } \\
\text { "Casas del hombre" }\end{array}$ & 2005 & Municipal & 2011 & $\begin{array}{c}\text { Obras } \\
\text { paralizadas }\end{array}$ & $\begin{array}{l}\sin \\
\text { concluir }\end{array}$ \\
\hline & (obra nueva) & Museo Alto Bierzo & 2004 & Municipal & 2006 & Completado & 2008 \\
\hline \multirow[t]{2}{*}{ FABERO } & Pozo Julia & \multirow{2}{*}{ Parque minero } & 2007 & $\begin{array}{l}\text { Municipal - } \\
\text { Asociación }\end{array}$ & 2007 & Completado & 2008 \\
\hline & Pozo Viejo & & 2010 & Municipal - JCyL & 2017 & Completado & 2018 \\
\hline PÁrAmo & (réplica) & Mina-museo & 2008 & Municipal & 2010 & completado & 2011 \\
\hline \multirow[t]{4}{*}{ Ponferrada } & Herrería de Compludo & Herrería visitable & 1986 & $\begin{array}{l}\text { Propietario } \\
\text { particular }\end{array}$ & - & - & 1986 \\
\hline & Estación MSP & $\begin{array}{l}\text { Museo Municipal del } \\
\text { Ferrocarril }\end{array}$ & 1996 & $\begin{array}{l}\text { Municipal - } \\
\text { Asociación }\end{array}$ & 1997 & Completado & 1999 \\
\hline & Centrales térmicas MSP & $\begin{array}{c}\text { Museo } \\
\text { Fábrica de Luz }\end{array}$ & 2007 & Estatal & 2009 & Completado & 2011 \\
\hline & $\begin{array}{l}\text { Central térmica } \\
\text { Compostilla }\end{array}$ & $\begin{array}{c}\text { Museo Nacional de la } \\
\text { Energía }\end{array}$ & 2007 & Estatal & 2008 & $\begin{array}{l}\text { Obras } \\
\text { paralizadas }\end{array}$ & $\begin{array}{l}\sin \\
\text { concluir }\end{array}$ \\
\hline $\begin{array}{l}\text { TORAL DE LOS } \\
\text { VADOS }\end{array}$ & Estación de RENFE & Museo del ferrocarril & 2004 & $\begin{array}{c}\text { Municipal- } \\
\text { Asoc. - CIUDEN }\end{array}$ & 2010 & Completado & $2010 / 15$ \\
\hline $\begin{array}{c}\text { TORRE DEL } \\
\text { BIERZO }\end{array}$ & $\begin{array}{c}\text { Instalaciones grupo } \\
\text { Viloria }\end{array}$ & $\begin{array}{c}\text { Museo de la Memoria } \\
\text { Minera }\end{array}$ & 2005 & $\begin{array}{c}\text { Fundación } \\
\text { privada }\end{array}$ & 2018 & $\begin{array}{c}1 / 3 \text { fase } \\
\text { completada }\end{array}$ & 2019 \\
\hline VILLABLINo & Ramales ferroviarios & Vía verde & 2014 & $\begin{array}{l}\text { Municipal- } \\
\text { Junta Vecinal }\end{array}$ & 2015 & Completado & 2018 \\
\hline \multirow{2}{*}{$\begin{array}{l}\text { VILLAGATÓN- } \\
\text { BRAÑUELAS }\end{array}$} & Estación de RENFE & Museo del ferrocarril & 2015 & Municipal & 2017 & Completado & $2017 / 19$ \\
\hline & Pontón ferroviario & $\begin{array}{l}\text { Recreación "Mina } \\
\text { Rinconín" }\end{array}$ & ¿? & $\begin{array}{l}\text { Municipal - } \\
\text { Asociación }\end{array}$ & ¿? & Completado & 2017 \\
\hline
\end{tabular}

Fuente: Elaboración propia (2019)

La promoción de recursos interpretativos del pasado minero se identifica complementaria a una voluntad de diversificación económica de la zona apoyada en los espacios naturales protegidos, el impulso del turismo rural y los espacios culturales UNESCO. Villablino, por ejemplo, promueve la transformación del antiguo edificio de las escuelas de Rioscuro para alojar un aula de interpretación de los castros de la Laciana, la construcción del centro de cría del urogallo en Caboalles de Arriba, la recuperación de la casona familiar y Escuelas de Sierra Pambley para centro educativo y museo etnográfico, o la rehabilitación de la lechería de Sosas "la Popular". Todos estos equipamientos están vertebrados por la vía verde de Laciana que aprovecha los antiguos ramales ferroviarios, y que, superada la polémica acerca de su preservación para uso ferroviario, ofrece un eje conector similar a la Senda del Oso de la cuenca asturiana estudiado por Benito (1997). La promoción del turismo natural impulsó la adaptación de las antiguas escuelas de Palacios del Sil para un Centro de Interpretación (2006), y en Vega de Espinareda se planteó un centro de recepción de 
visitantes de los Ancares. También se barajó un Centro de Interpretación del Castaño en Santa Marina del Sil, promovido por ADESPER (2003), iniciativa que finalmente se acometió en Berlanga (Fabero), donde también se promovía un parque temático de los hongos (2008). En Páramo del Sil se propuso en 2008 una Casa de las Ciencias, mientras que Fabero, Bembibre y Robles de Laciana se dotaron de aulas geológicas. A este conjunto de instalaciones, se suma el despliegue de hasta 7 centros divulgativos en el área de las Médulas, así como otro tipo de equipamientos interpretativos que no están directamente ligados a municipios o espacios mineros.

La materialización de las distintas iniciativas ha sido desigual, y ha estado condicionado por el acceso a la propiedad de las diversas instalaciones por parte de los agentes promotores, pero también por la dilatación de los procedimientos burocráticos y el coste de la ejecución y/o puesta en marcha de proyectos a menudo sobredimensionados, o por dificultades económicas de las administraciones locales para mantenerlos abiertos. El tren turístico se dilata en el tiempo, sin que todavía se hayan hecho públicos los proyectos planteados por la Junta de Castilla y León, la Fundación CIUDEN y la extinta FEVE en 2011. Por otra parte, el parque minero de Fabero, que en primera instancia no planteaba el empleo de instalaciones históricas al presentarse en 1998, ha salido adelante gracias a la cesión, en 2007, de UMINSA del Pozo Viejo y el Pozo Julia, cuyas instalaciones han ofrecido un recurso basado en la autenticidad de los espacios, a lo que se ha añadido la implicación de la asociación de exmineros, que ha suplido la falta de ejecución del proyecto planteado por la Junta de Castilla y León en 2011, donde se incluía una mina imagen y una llamativa intervención arquitectónica. Sustancialmente reducida se ha visto la obra acometida en la central térmica de Compostilla I para alojar las instalaciones museográficas de la Fundación CIUDEN, que desde el 2011 opera la línea cultural desde la antigua central de MSP, reconvertida en el museo "Fábrica de luz". La construcción de las distintas piezas del ecomuseo de Bembibre, entre las que se encontraba la "Casa del Carbón", se vio interrumpida apenas arrancaron las obras en 2011.

Sin haber superado la crisis económica, ayuntamientos y pedanías han relanzado iniciativas de puesta en valor, de corte más sencillo, apoyadas en el movimiento asociativo. En los últimos años se ha abierto el centro de interpretación del ferrocarril de Torre del Bierzo y reabierto el de Toral de los Vados. Y es que el papel de las asociaciones de antiguos mineros, vecinos y juntas vecinales, Amigos del Ferrocarril, el Instituto de Estudios Bercianos (IEB) o Promonumenta, se evidencia como un agente activo en la puesta en marcha y el mantenimiento de las iniciativas culturales, que con pequeñas actuaciones ofrecen recursos en el itinerario turístico y suplen la paralización de las grandes intervenciones de impulso autonómico y estatal. Otras iniciativas se ocupan en la reutilización de bocaminas o los primeros metros de galerías para alojar pequeños espacios divulgativos, como en La Silva, o lugares de culto, como en el caso de Labaniego (2017), alrededor de las que proponer rutas ciclo-peatonales. Lamentablemente el escaso eco de estas intervenciones y la falta de coordinación entre administraciones reduce su difusión y conocimiento, y limita la posibilidad de articular una red de hitos ligados a la minería en el territorio. En los últimos años se ha planteado la incorporación al circuito turístico de Laciana de parte de las instalaciones de la Mina Escuela de la Fundación Santa Bárbara (2018), y en 2019 la Fundación Memoria Minera ha reabierto su proyecto museístico en Torre del Bierzo.

\subsubsection{Equipamientos públicos}

A la hora de considerar la reutilización del legado minero e industrial de estos territorios, hay que considerar también otros programas públicos, con más recorrido incluso que el de los museos y equipamientos interpretativos. En Ponferrada la Fábrica de curtidos Matinot y su antiguo molino, alojan desde 1994 la Escuela Taller Municipal, trasladada de su primera sede (1985) que fuera Antiguo matadero municipal, y hoy es centro cívico. Las Casas de Ingenieros de MSP y las zonas de esparcimiento de la "Finca del Belga" en la misma ciudad pasaron en 1986 a gestión municipal, y fueron abiertas como parque, equipamientos juveniles y Conservatorio de Música, hoy Sede de la Policía Municipal. También las escuelas de MSP de Villablino se han reconvertido en centro cívico. En el debate público se encuentra la propuesta de recuperación de los jardines y molino de la Fundación Fustigueras.

\subsubsection{Iniciativas lúdico-culturales de capital privado}

La implicación de agentes privados no se puede pasar por alto. La "Casa Salomé”, de Toreno, mantiene desde 1962 los servicios de hostelería y restauración en la residencia de solteros de MSP de la localidad. En Laciana, cerrado el 
establecimiento de Villaseca, en 2017 se reabrieron las instalaciones de la Residencia de Caboalles como hotel, tras descartarse su utilización por parte de la Junta como centro de menores tutelados. La Asociación ASPRONA Bierzo cuenta para sus instalaciones de personas con discapacidad con edificios del poblado de productores Bárcena, desde 1987, y de Compostilla, desde 2012. La Confederación Hidrográfica mantiene sus oficinas también en el poblado de Bárcena.

En 1998 parte de las instalaciones del Coto minero Vivaldi fueron reconvertidas en club de golf y finca de eventos, y en 2017 algunos edificios del Grupo Lumajo fueron adaptados para alojar una fábrica de cerveza. Para salvar del abandono los "Cuarteles Mineros" de Tremor, el ayuntamiento de Igüeña ha sacado a la venta estas viviendas a particulares.

La central hidroeléctrica Higálica se adaptó a oficinas que hoy ocupa Naturgy; molinos de Bembibre, Quintela, Molinaseca o Vega de Espinareda se han adaptado a establecimientos de restauración, así como el lagar de Montejos. En Villafranca del Bierzo dos antiguas fábricas de alcoholes y conservas fueron adaptadas para uso hostelero y enoturismo.

\subsection{Los archivos de empresa: un patrimonio amenazado}

La importancia del Patrimonio Documental de los archivos de empresa viene recogida en la Carta del Bierzo, así como la necesidad de su inventariado. Si bien constan en hemeroteca las manifestaciones de gestores locales de poner en marcha un archivo de la minería, no se han identificado medidas en este sentido. Por lo general, el cierre de las instalaciones mineras y fabriles ha ido acompañado por el abandono de la documentación, sin que las administraciones hayan realizado seguimiento alguno del valor de estos fondos, ni definido pautas para las administraciones concursales que liquidan las empresas. Los fondos de las empresas mineras del Bierzo no están incluidos en los censos de "archivos históricos" autonómicos, ni consta que esta administración disponga de un censo de archivos de empresas de la minería. Por iniciativa propia, los fondos de Combustibles Fabero, S.A., hoy legados a Carbones Josepín, fueron inscritos en el Censo-Guía de los Archivos de España e Iberoamérica. El Museo de la Minería y la Siderurgia de Castilla y León parece haberse hecho responsable de una reducida parte de los fondos de la centenaria Minero-Siderúrgica de Ponferrada que conservaba CMC. No se ha podido confirmar el destino de los fondos de las empresas mineras del grupo UMINSA, bajo administración concursal; los fondos locales de ENDESA en Ponferrada fueron saqueados por particulares, ante la desidia municipal, cuando las instalaciones pasaron al Ayuntamiento en 2003.

\subsection{Estrategias de difusión del patrimonio minero industrial y el reto de la coordinación}

Iniciativas culturales de distinto tipo, exposiciones, publicaciones, homenajes y festejos ligados al pasado minero, ferroviario e industrial impulsados por administraciones locales y asociaciones son frecuentes. Fabero, Villablino y Ponferrada también han sido escenarios de congresos científicos, cursos y jornadas técnicas especializadas en patrimonio geológico-minero e industrial. También el IPCE ha celebrado alguna de las sesiones de Buenas Prácticas en Patrimonio Industrial en las instalaciones del Museo de CIUDEN.

La ausencia de desarrollo en Castilla y León de una normativa sobre el paisaje, que regule la aplicación del Convenio Europeo del Paisaje (2000), y la falta de continuidad de las políticas de conservación planteadas con el inventario, mediante el desarrollo de un programa de actuaciones de rehabilitación, gestión y protección del legado minero e industrial de la zona, supone un serio problema. Si bien, a nivel local cabe plantear la pertinencia de mejorar sustancialmente la coordinación entre las diferentes administraciones locales, que permitiera promover una actualización del inventario o establecer criterios comunes de protección e impulsar iniciativas de conservación preventiva entre propietarios particulares, lo cierto es que resulta muy limitada su capacidad técnica y económica para llevar a la práctica una iniciativa a gran escala que pudiera plantear la adquisición de aquellos conjuntos históricos más emblemáticos en concurso de acreedores para evitar su ruina. En este sentido, el Consejo Comarcal del Bierzo o la Diputación Provincial debieran constituir las figuras de liderazgo y coordinación.

En el camino hacia la mejora de la colaboración entre instituciones cabe mencionar que desde 2019 el Museo CIUDEN y el Centro de Interpretación de las Médulas gestionado por el IEB ofrecen entrada única sus instalaciones. También la 
Cátedra UNED-ULE de Turismo Sostenible y Desarrollo Local ha aparecido como potencial instrumento de coordinación, investigación y marco de formación y organización de agentes locales públicos y privados.

\section{Resultados y conclusiones}

Una aproximación general a los proyectos planteados en el periodo 1998-2006 ofrece unos resultados poco positivos. Falta de previsión, lentitud de los procesos, y escala sobredimensionada de las iniciativas explican el fracaso de un conjunto de recursos interpretativos y turísticos, sustituido con iniciativas locales más sencillas que, no obstante, requieren urgentemente coordinación en red y difusión para mejorar sus rendimientos.

Una regulación urbanística municipal coordinada y sensible con el legado edificado del pasado minero industrial en primer lugar, y la propiedad de las instalaciones mineras se identifican como claves básicas para la conservación de los bienes inmuebles. Sin embargo, la ausencia de un programa de actuaciones, conservación y uso sostenible se plantea como principal reto para la gestión de los bienes. El acceso a la propiedad de las instalaciones o el compromiso de los propietarios se hace imprescindible; pero también el impulso de los distintos agentes locales en el desarrollo y seguimiento de acciones de puesta en valor. El caso de Fabero se puede plantear como un ejemplo de buenas prácticas, donde las compañías mineras cedieron al Ayuntamiento el grueso de las instalaciones; en estos momentos un consistorio con menguadas arcas y amenazado por la despoblación encabeza con las asociaciones locales un programa de puesta en valor de ese legado, apoyados desde la administración autonómica, que ha promovido la revisión de la regulación urbanística, incluido figuras de protección y asesoramiento técnico, y ayudas económicas para proyectos de conservación.

Así pues, en las últimas tres décadas se han desarrollado diversas iniciativas de musealización y promoción turística encaminadas a poner en valor la cultura industrial como un pilar del desarrollo local. Sin embargo, varios de los grandes proyectos planteados hace una década se han visto demorados, cancelados o interrumpidos por falta de financiación; y se echa en falta una planificación territorial. Ayuntamientos, pedanías, comunidades locales y/o particulares han actuado como mantenedores de modestas iniciativas, frecuentemente descoordinadas, intentando completar la principal oferta cultural asociada a estos territorios: el yacimiento romano de las Médulas y el Camino de Santiago Francés a su paso por la comarca. Más allá de las actuaciones museográficas e interpretativas, el Bierzo y Laciana cuentan con un amplio conjunto de recursos disponibles ligado al pasado minero y susceptible de ofrecer una red accesible a los visitantes.

\section{Referencias}

Alonso Santos, J. (2011). Planificación y práctica urbana en la ciudad de Ponferrada: el PGOU 2007. Ciudad y territorio, 167, 131151.

Andrieux, J.Y. (1992). Architectures du travail. Presses universitaries de Rennes, Rennes.

Aparicio Rabanedo, E. (2019). La museografía en el proyecto de creación del Museo Nacional de la Energía en Ponferrada (León). RdM. Revista de Museología, 76, 59-74.

Balboa de Paz, J. A. (1997). Industria y Arqueología industrial en el Bierzo. Estudios bercianos, 23, 105-117.

Benito del Pozo, P. (1997). Dinamización del territorio y patrimonio industrial. Polígonos. Revista de Geografia, 7, 123-131.

Benito del Pozo, P. (2009). Herramientas para intervenir en el patrimonio: el inventario de patrimonio industrial de Castilla y León. Polígonos. Revista de Geografia, 19, 181-191.

Benito del Pozo, P., \& López González, A. (2008). El uso turístico del patrimonio industrial de las ciudades. M.A Troitiño y otros (Coords.), Destinos turísticos: viejos problemas, ¿nuevas soluciones? 167-178. Universidad Castilla-La Mancha, Cuenca.

Cañizares Ruíz, M. del C. (2011). Protección y defensa del patrimonio minero en España. Scripta Nova, 361.

Conlin, M., y Jolliffe, L. (2010). Mining Heritage and Tourism. A Global Synthesis. Londres: Routledge.

Conti, S. (2011). Recalificación y uso de los suelos industriales abandonados. En Benito del Pozo (Dir.), Areas empresariales, suelo industrial y logística: análisis y procesos en el territorio , 15-32. Aranzadi, Pamplona. 
Cueto Alonso, G. J. (2009). Reutilización turística del patrimonio minero de Cantabria. Cuadernos de Turismo, 23, 69-87.

Goodall, G., y Beech, J. (2006). The Management of Heritage and Cultural Tourism. En J. Beech \& S. Chadwick (Eds.), The Business of Tourism Management, 485-505. Prentice H, Harlow.

Hidalgo Giralt, C. (2011). La puesta en valor turística del patrimonio minero-industrial y ferroviario del Arco Cantábrico. Las experiencias de los Valles Mineros, la Montaña Palentina y el Bierzo. De Re Metallica, 17, 75-84.

Hortelano Mínguez, L. A. (2011a). Turismo minero en territorios en desventaja geográfica de Castilla y León: recuperación del patrimonio industrial y opción de desarrollo local. Cuadernos de Turismo, 27, 521-539.

Hortelano Mínguez, L. A. (2011b). La adecuación turística de las cuencas mineras del carbón de León y Palencia: la preservación de la memoria y el uso alternativo de las instalaciones. En Espacios y destinos turísticos en tiempos de globalización y crisis. XII Coloquio de Geografia del Turismo, Ocio y Recreación, pp. 293-304. Universidad Carlos III, Madrid.

Monteserín Abella, O. (2008). Turismo y desarrollo territorial: los planes de dinamización turística en la interpretación y puesta en valor del territorio. Tesis Doctoral. Universidad Complutense, Madrid. 